\title{
Clinical Reasoning: A teenager with persistent headache
}

Yang Hu, MD, * Zhouping Tang, MD, PhD, * Wenhao Zhu, MD, and Shabei Xu, MD, PhD

Neurolog ${ }^{\circledR}$ 2019;92:e1526-e1531. doi:10.1212/WNL.0000000000007184

\author{
Correspondence \\ Dr. Xu \\ xushabei@126.com
}

\section{Section 1}

A previously healthy 15-year-old boy with no relevant medical history presented with 3 weeks of severe, persistent, holocephalic pain associated with nausea and vomiting, without fever or alteration of consciousness. A brain MRI including magnetic resonance angiography and magnetic resonance venography (MRV) at a local hospital was normal. A lumbar puncture revealed a CSF pressure of $240 \mathrm{~mm} \mathrm{H}_{2} \mathrm{O}$. An intracranial infection was suspected based on clinical symptoms and signs. He received empiric antiviral therapy and rehydration for 1 week, but there was no relief of symptoms. He was subsequently transferred to our hospital.

On admission, the patient endorsed poor spirits and poor dietary intake. He denied any neurologic deficits and his vital signs were normal. The neurologic examination revealed meningeal signs and symmetric hyperactive deep tendon reflexes of both lower extremities.

\section{Questions for consideration:}

1. What is the differential diagnosis for progressive headache?

2. What tests could help narrow the differential diagnosis for this patient?

\section{GO TO SECTION 2}




\section{Section 2}

Headache is a common symptom in the general population. This includes primary headache disorders such as migraine or tension-type headaches or secondary headache disorders that may be due to infection, sinusitis, cerebral venous sinus thrombosis (CVST), or neoplastic disease. When headaches develop acutely without any history of prior headache, a secondary headache disorder should be considered. If there is clinical evidence of infection, considerations include sinusitis, pharyngitis, or meningitis. Otherwise, a space-occupying lesion or vascular process can be considered. ${ }^{1}$

Considering the differential diagnosis above, the diagnostic battery for this patient includes an MRI with contrast to evaluate for mass lesions and meningeal enhancement, MRV to rule out CVST, serum studies, and a lumbar puncture to evaluate for opportunistic infections. Serum studies revealed a normal white blood cell count $\left(10.07 \times 10^{9} / \mathrm{L}\right)$, neutrophils $\left(7.26 \times 10^{9} / \mathrm{L}\right)$, and homocysteine $(63.5 \mu \mathrm{mol} / \mathrm{L})$. The coagulation profile was slightly abnormal with prolonged prothrombin time (14.8 seconds), elevated D-dimer $(4.38 \mu \mathrm{g} / \mathrm{mL})$, and normal activated partial thromboplastin time (31.1 seconds). Other routine tests including urinalysis, erythrocyte sedimentation rate, procalcitonin, and C-reactive protein showed no abnormalities.

Lumbar puncture revealed a CSF pressure of $170 \mathrm{~mm} \mathrm{H}_{2} \mathrm{O}$. The cell count was normal and the CSF protein level was $513 \mathrm{mg} / \mathrm{L}$ (normal range 150-450 g/L). CSF cultures and cytology revealed no obvious abnormalities. Head CT, brain MRI (figure 1), and MRV scans (figure 2A) showed multiple CVSTs. Despite the relatively high sensitivity of MRV in confirming CVST, there is a small false-negative rate, ${ }^{2}$ and therefore repeat MRV testing is recommended.

\section{Question for consideration:}

1. What can cause multiple CVSTs in a formerly healthy adolescent with a negative family history of clotting disorders?

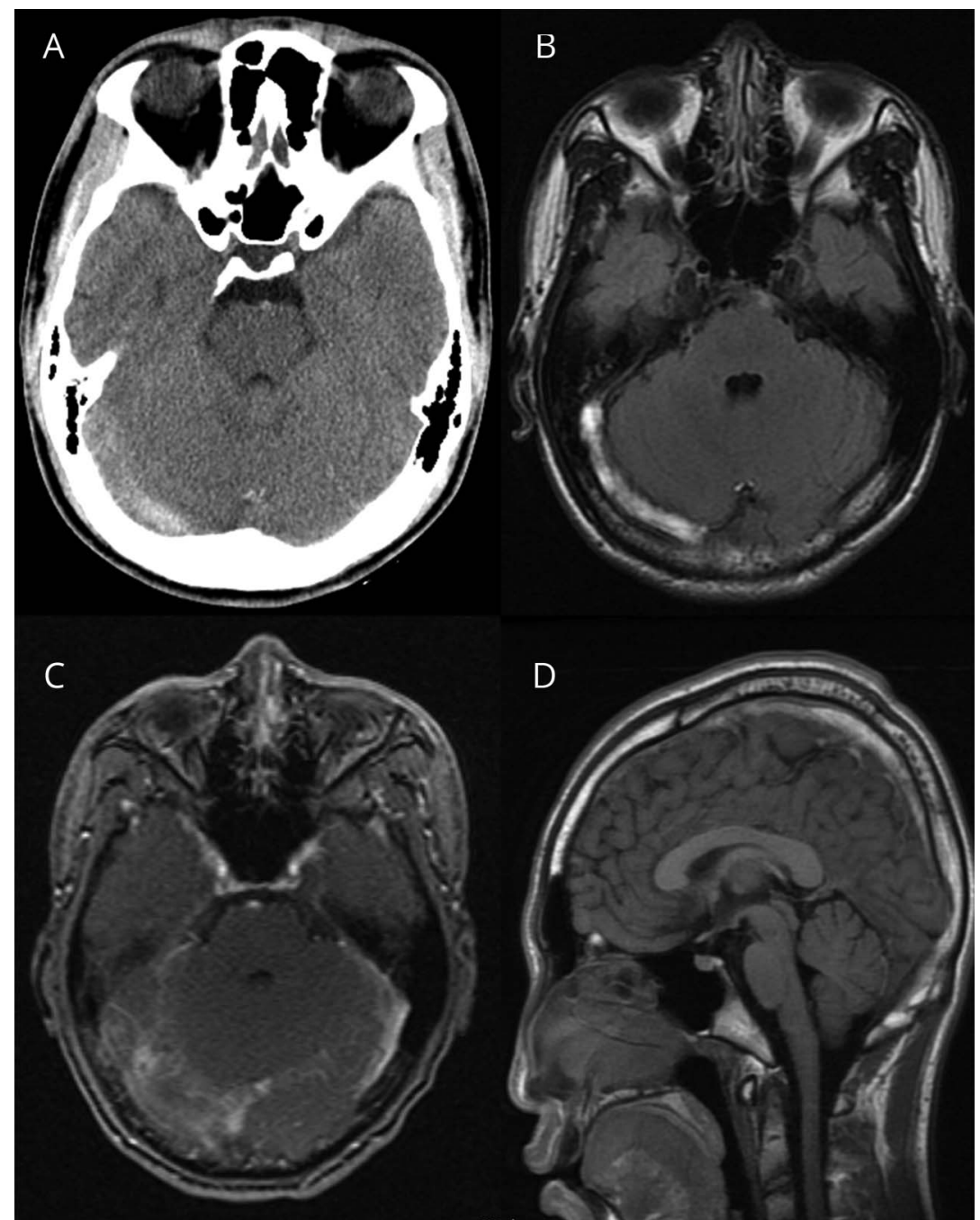

(A) Head CT. (B) Axial and (D) sagittal T1-weighted sequence and (C) axial contrast-enhanced T1-weighted MRI sequence show multiple cerebral venous sinus thromboses on admission. 
Figure 2 Magnetic resonance venography (MRV) reconstruction of the patient's cerebral veins

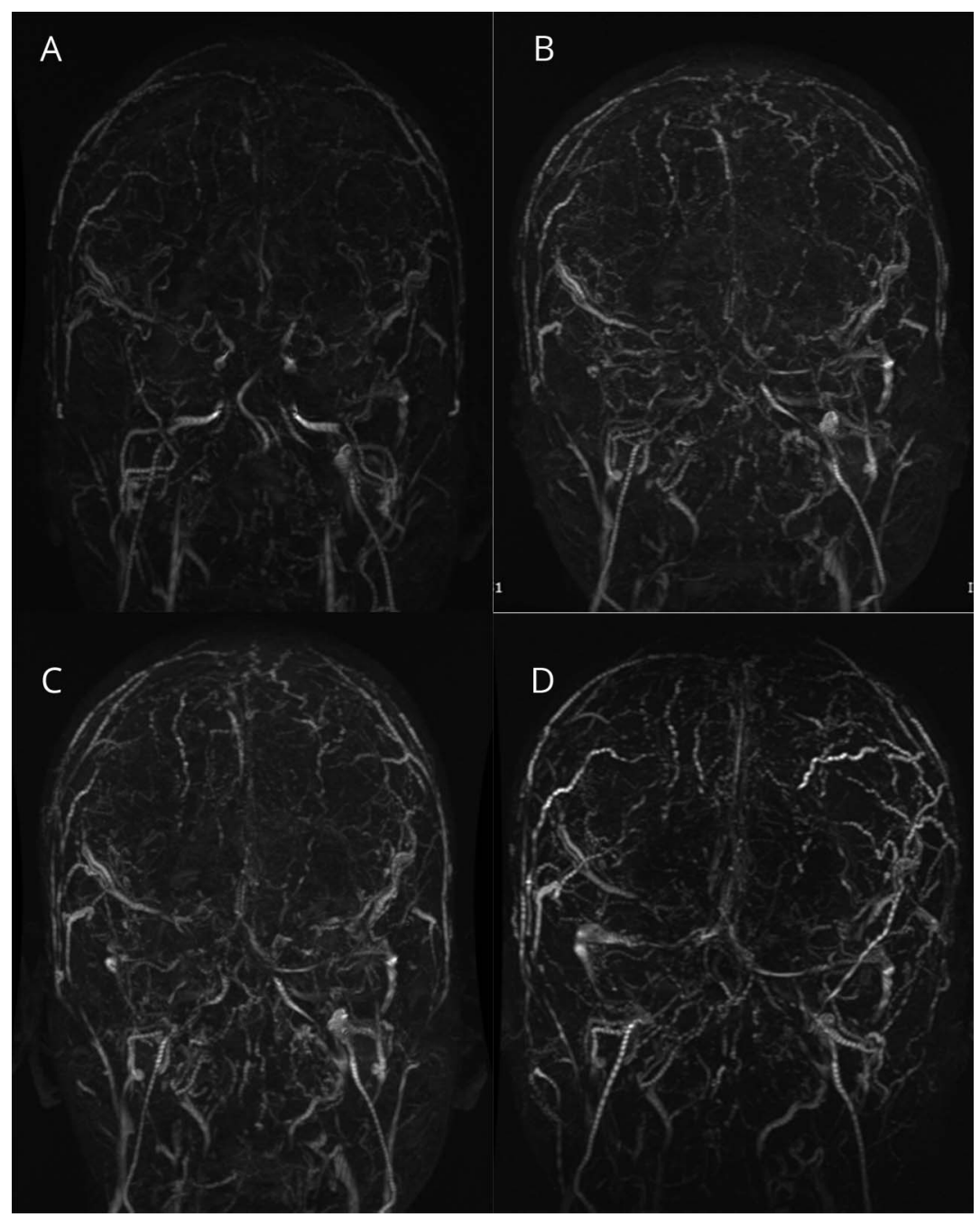

Coronal MRV reconstruction (A) on admission, (B) after 2 weeks, (C) after 1 month, and (D) after 6 months shows gradual return of normal venous blood flow.

\section{GO TO SECTION 3}



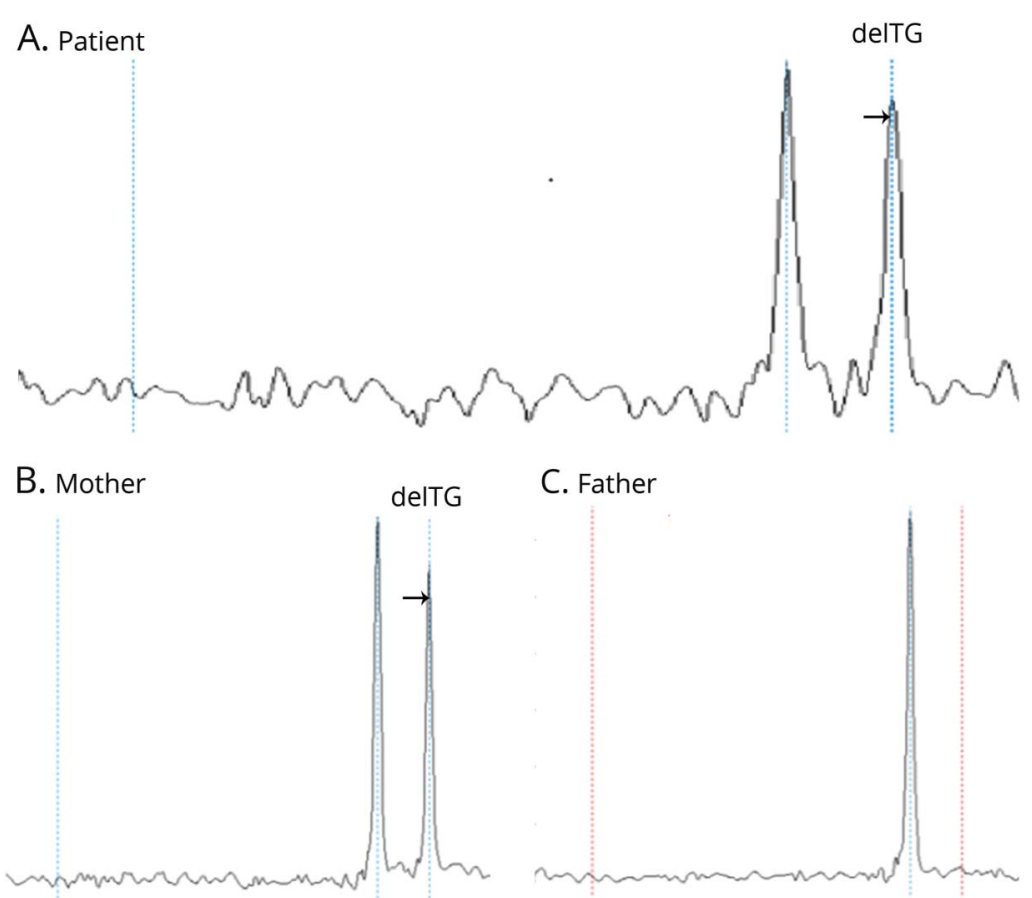

Results show a novel PROS1 frameshift mutation (PROS1, c.1751_1752delTG [p.Leu584ArgfsX7]; Het) on chromosome $3: 93595929$ of (A) the patient and (B) his mother but not (C) his father.

\section{Section 3}

CVST accounts for about $0.5 \%-1 \%$ of all strokes. The etiology generally includes comorbid medical conditions, pregnancy, dehydration, infection, medications (e.g., oral contraceptives, substance abuse), and unpredictable events (e.g., head trauma). ${ }^{3}$

We screened for risk factors associated with CVST. Rheumatic and immunologic examination, antineutrophil cytoplasmic antibodies, rheumatoid factor, and hormone concentrations were nearly normal. A screen for thrombotic disease revealed no antithrombin deficiency, protein C (PC) deficiency, or factor $\mathrm{V}$ Leiden mutation. The plasma protein $\mathrm{S}$ (PS) anticoagulant activity was $22 \%$, profoundly lower than the normal range.

PS deficiency (PSD) is a disorder of blood clotting and is present in $0.1 \%-0.3 \%$ of the general population and $1 \%-3 \%$ of people with incident venous thromboembolism. ${ }^{4}$ People with hereditary PSD have a 2- to 11-fold increased risk for developing a deep venous thrombosis of the lower limbs with or without pulmonary embolism. ${ }^{5}$ Hereditary PSD is caused by mutations in the PROS1 gene, which codes for PS. ${ }^{6}$

A written consent form, stating acceptance of the genetic testing, was signed by the patient and his parents. Thrombophilia-
Table Coagulation characteristics of the patient and his parents

\begin{tabular}{lllll}
\hline & Age, $\mathbf{y}$ & Sex & PS activity & Clinical information \\
\hline Patient & 15 & Male & 22 (Low) & CVST \\
\hline Mother & 37 & Female & 28 (Low) & No thrombosis \\
\hline Father & 41 & Male & 166 (Normal) & No thrombosis \\
\hline
\end{tabular}

Abbreviations: CVST = cerebral venous sinus thrombosis; PS = protein S Reference range: PS activity (male/female) $=77 \%-143 \% / 55 \%-123 \%$.

associated genes including but not limited to $A B C D 4, C B S$, MTHFR, MTR, MTRR, and MMADHC were assayed. A novel PROS1 frameshift mutation (PROS1, c.1751_1752delTG [p.Leu584ArgfsX7; Het]) that generates a premature stop codon was identified in the patient and his mother but not in his father (figure 3). Based on the single nucleotide polymorphism database, this suspected pathogenic mutation was extremely rare in the normal population. His parents underwent serum coagulation testing, which revealed that his mother also had a severe reduction in PS activity (table).

\section{Question for consideration:}

1. What treatment would you recommend for this patient? 


\section{Section 4}

The acute management of CVST involves controlling elevated intracranial pressure and treating the thrombosis. Guidelines recommend anticoagulation with a therapeutic dose of heparin as the primary treatment for CVST. For patients with CVST who are medically stable, treatment with a vitamin $\mathrm{K}$ antagonist should be initiated. ${ }^{3}$ The patient received mannitol and glycerol fructose to reduce intracranial pressure. His headache improved after 1 week of treatment. At the same time, he was given low-molecularweight heparin (LMWH) $4.25 \mathrm{kU}$ twice daily for 2 weeks, followed by dabigatran etexilate, a direct thrombin inhibitor metabolized through the cytochrome $P 450$ system, at $110 \mathrm{mg}$ twice daily. The patient was discharged after clinical improvement. His cerebral MRV showed return of normal venous blood flow 6 months after his discharge (figure 2, B-D).

\section{Discussion}

We report a teenager who presented with persistent headache due to multiple CVSTs due to familial PSD with a novel PROS1 frameshift mutation. Although CVST is characterized by a variety of symptoms, including headache, seizure, lethargy, focal neurologic signs, convulsions, and coma, headache is the most frequent symptom and occurs in $75 \%-95 \%$ of all cases. Cerebral infection can be differentiated from CVST by CSF testing and the treatment is different for the 2 diseases. In addition, elevated serum D-dimer can be an important indicator of CVST. $^{3}$ This case highlights that CVST cannot be excluded in a patient with persistent headache, even if there is no personal or family history of thrombosis and even after a single normal MRV scan.

Thrombophilia can be hereditary or acquired. Hereditary thrombophilia is caused by genetic defects that result in abnormal functional protein levels such as antithrombin deficiency, PS deficiency, PC deficiency, factor V Leiden mutation, or factor II G20210A mutation. Acquired thrombophilia can be due to antiphospholipid syndrome, malignant tumors, or a prothrombotic state (surgery, trauma, prolonged immobilization). Hyperhomocysteinemia is also a risk factor for arterial and venous thrombosis that can lead to CVST. ${ }^{7}$ This patient presented with high levels of homocysteine $(>20$ $\mathrm{mmol} / \mathrm{L}$ ) and PSD. After genetic testing of the patient and his family, a diagnosis of familial PSD was made.

Hereditary PSD is a haploinsufficiency disorder associated with an increased risk of venous thrombosis. Individuals with this condition do not have enough functional PS to inactivate clotting proteins, which results in the increased risk of developing abnormal blood clots. Rarely, PSD is acquired in patients with liver disease, warfarin use, vitamin $\mathrm{K}$ deficiency, pregnancy, and other conditions. ${ }^{5}$
PS is encoded by the PROS1 gene located on chromosome 3 at 3q11.2. The genetic basis of PSD is heterogeneous. More than 200 mutations in PROS1 have been described, mainly missense or nonsense mutations. Null mutations result in severe PS defects by reducing PS synthesis. Missense mutations can have severe, intermediate, or mild consequences. ${ }^{6}$ Zhang et al. ${ }^{8}$ reported a novel PROS1 mutation causing PSD in a family after a proband was diagnosed with pulmonary embolism. CVST is rarely seen in association with PSD. Amaral et al. ${ }^{9}$ reported a case of CVST in a young adult with familial PSD but the patient and his family members did not receive PROS1 genetic testing.

We detected a PROS1 frameshift mutation in a patient with CVST that, to our knowledge, has not been reported in the literature. The mutation in the affected family members (patient and mother) was consistent with their reduced PS level, indicating that this mutation was the molecular basis of the PSD and CVST.

Guidelines recommend heparin as the primary treatment for CVST. The optimal duration of anticoagulant treatment is currently being evaluated, generally between 3 and 12 months, or longer in rare cases. ${ }^{3}$ Although heparin and warfarin have been used historically, direct oral anticoagulants (DOACs) such as dabigatran, apixaban, and rivaroxaban have been reported to be alternatives. ${ }^{10}$ Our patient received dabigatran etexilate, after $\mathrm{LMWH}$, and recovered both clinically and radiographically without bleeding events.

From our experience, for patients presenting with persistent headache, one should consider CVST, even if there is no history of thrombotic events. D-dimers and CSF testing are important to differentiate CVST from cerebral infection in the early stage. Once hereditary PSD is considered, genetic testing is recommended for both the patient and family members. Furthermore, while the newer DOACs have been applied in CVST, further robust studies are needed to validate the therapeutic effect of DOACs in inherited thrombophilia.

\section{Acknowledgment}

The authors thank the Tongji Hospital for providing patient information.

\section{Study funding}

No targeted funding reported.

\section{Disclosure}

Y. Hu reports no disclosures relevant to the manuscript. Z. Tang receives research support from the National Natural Science Foundation of China and Clinical Research Physician Program of Tongji Medical College, HUST. W. Zhu receives research support from the National Natural Science Foundation of China. S. Xu receives research support from the Clinical Research Physician Program of Tongji Medical College, HUST. Go to Neurology.org/N for full disclosures. 


\section{Appendix Authors}

\begin{tabular}{|c|c|c|c|}
\hline Name & Location & Role & Contribution \\
\hline $\begin{array}{l}\text { Yang Hu, } \\
\text { MD }\end{array}$ & $\begin{array}{l}\text { Huazhong University } \\
\text { of Science and } \\
\text { Technology, Wuhan } \\
\text { Hubei, China }\end{array}$ & Author & $\begin{array}{l}\text { Designed and } \\
\text { conceptualized study, } \\
\text { analyzed the data, } \\
\text { literature review, } \\
\text { clinical data collection, } \\
\text { drafted the article }\end{array}$ \\
\hline $\begin{array}{l}\text { Zhouping } \\
\text { Tang, MD, } \\
\text { PhD }\end{array}$ & $\begin{array}{l}\text { Huazhong University of } \\
\text { Science and Technology, } \\
\text { Wuhan Hubei, China }\end{array}$ & Author & $\begin{array}{l}\text { Analyzed the data, } \\
\text { literature review, } \\
\text { clinical data collection }\end{array}$ \\
\hline $\begin{array}{l}\text { Wenhao } \\
\text { Zhu, MD }\end{array}$ & $\begin{array}{l}\text { Huazhong University of } \\
\text { Science and Technology, } \\
\text { Wuhan Hubei, China }\end{array}$ & Author & $\begin{array}{l}\text { Major role in the } \\
\text { acquisition of data }\end{array}$ \\
\hline $\begin{array}{l}\text { Shabei } \\
\text { Xu, MD, } \\
\text { PhD }\end{array}$ & $\begin{array}{l}\text { Huazhong University of } \\
\text { Science and Technology, } \\
\text { Wuhan Hubei, China }\end{array}$ & Author & $\begin{array}{l}\text { Interpreted the data, } \\
\text { revised the manuscript } \\
\text { for intellectual content }\end{array}$ \\
\hline
\end{tabular}

\section{References}

1. Ducros A, Bousser MG. Thunderclap headache. BMJ 2013;346:e8557.

2. Gao L, Xu W, Li T, et al. Accuracy of magnetic resonance venography in diagnosing cerebral venous sinus thrombosis. Thromb Res 2018;167:64-73.

3. Saposnik G, Barinagarrementeria F, Brown RD, Jr., et al. Diagnosis and management of cerebral venous thrombosis: a statement for healthcare professionals from the American Heart Association/American Stroke Association. Stroke 2011;42: 1158-1192.

4. Cohoon KP, Heit JA. Inherited and secondary thrombophilia. Circulation 2014;129: 254-257.

5. Lipe B, Ornstein DL. Deficiencies of natural anticoagulants, protein C, protein S, and antithrombin. Circulation 2011;124:e365-e368.

6. García de Frutos P, Fuentes-Prior P, Hurtado B, Sala N. Molecular basis of protein S deficiency. Thromb Haemost 2007;98:543-556.

7. Connors JM. Thrombophilia testing and venous thrombosis. N Engl J Med 2017;377: 1177-1187.

8. Zhang $\mathrm{Y}$, Yang $\mathrm{H}$, Chen $\mathrm{Q}$, et al. A novel PROS1 mutation, c.74dupA, was identified in a protein S deficiency family. Thromb Res 2016;148:125-127.

9. Amaral FM, Silva CR, Borém MG, Miranda-Vilela AL. Cerebral venous thrombosis in young adult with familial protein S deficiency. Blood Coagul Fibrinolysis 2015;26: 342-345.

10. Patel SI, Obeid H, Matti L, Ramakrishna H, Shamoun FE. Cerebral venous thrombosis: current and newer anticoagulant treatment options. Neurologist 2015;20: 80-88. 